\title{
Clinical Outcome and Operative Findings with Ectopic Pregnancy at Tertiary Medical College \& Hospital
}

\author{
Fahmida Sultana*1, Gulshan Ara², Sayma Afroz ${ }^{3}$, Rokshana Parvin Nupur ${ }^{4}$, Mashah Binte Amin ${ }^{5}$
}

\begin{abstract}
Introduction: An ectopic pregnancy is an emergency condition worldwide now a days which defined as a pregnancy that progresses after implantation of the blastocyst anywhere other than the endometrium lining the uterine cavity. Objective: In this study our main goal is to identify clinical outcome and operative situation in patients. Materials and Methods: This descriptive study was performed from January 2015 to December, 2018 at tertiary medical College \& Hospital. During the study 200 patients were evaluated and data was extracted from socio-demographic, menstrual, obstetric and clinical history of the patients. Results: most of the patients belong to 30 years $(19.7 \%)$ age group and history of pelvic infection (26.26\%), induced abortion (17.4\%), previous MR (16.26\%) and sub fertility $(11.25 \%)$ were common risk factor in ectopic pregnancy found in the study. Also majority of the patients faced laparotomy followed by right sided salphinogectomy (40.40\%) which was the most common operation. Conclusion: quick diagnosis, classifying of risk factors and timely intervention in the form of surgical treatment is necessary for reduction mortality rate in ectopic pregnancy.
\end{abstract}

Keywords: Ectopic pregnancy, Laparotomy, Pelvic infection.

Number of Tables: 05; Number of Figures: 04; Number of References: 22; Number of Correspondence: 07.

*1. Corresponding Author: Dr. Fahmida Sultana Assistant Professor, Department of Obs and Gynae Enam Medical College and Hospital, Savar, Bangladesh. Email: fahmidasultana00@gmail.com

2. Dr. Gulshan Ara

Professor and Head

Enam Medical College and Hospital, Savar, Bangladesh.

3. Dr. Sayma Afroz

Assistant Professor, Department of Gynae

Enam Medical College and Hospital, Savar, Bangladesh.

4. Dr. Rokshana Parvin Nupur

Assistant Professore, Department of Obst and Gynae

Enam Medical College and Hospital, Savar, Bangladesh.

5. Dr. Mashah Binte Amin

Associate Professor, Department of Radiology and Imaging Enam Medical College and Hospital, Savar, Bangladesh.

\section{Introduction}

Parenthood, an eternal, universal and inherent dream which every woman has. This dream may not always be satisfying. One of this is ectopic pregnancy: A pregnancy which is associated with life threatening condition $^{1}$. The frequency of ectopic pregnancy varies from place to place even in the same country ${ }^{2}$. Recent proof indicate that the occurrence of ectopic pregnancy such as in France- 15 per 1000 pregnancies and in India-1 in 100 deliveries. In the U.K. there are about 11,000 cases of ectopic pregnancies per year (incidence 11.5) per 1000 pregnancies with 4 deaths $^{3}$. The number of ectopic pregnancies has greater than before in the past few decades in the U.S.A. Established on hospital discharge data, the occurrence of ectopic pregnancy has increased from 4.5 cases per 1000 pregnancies in 1970 to 19.7 cases per 1000 pregnancies in 19924. In the industrialized world, among $1 \%$ and $2 \%$ of all reported pregnancies are ectopic pregnancies 5 . The incidence is thought to be higher in developing countries, but specific numbers are unknown. Although the incidence in the developed world has remained relatively static in recent years, between 1972 and 1992 there was an estimated six-fold rise in the incidence of ectopic pregnancy. Ectopic pregnancy is a momentous cause for maternal morbidity $\&$ mortality as well as fetal $\operatorname{loss}^{6}$. There has been a momentous increase in the number of cases of ectopic pregnancy. Pelvic inflammatory disease, induced abortion, history of infertility, use of intrauterine contraceptive device (IUCD) pelvic surgery, STDs are the causative risk factor for ectopic pregnancy ${ }^{7}$.
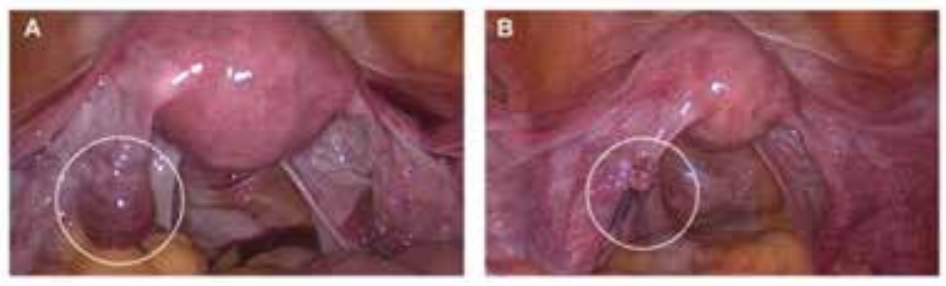

Tubal ectopic pregnancy which has been removed by salpingectomy ${ }^{8}$.

In this study our main objective is to identify clinical outcome and operative situation with ectopic pregnancy at tertiary medical College \& Hospital.

Objective

General objective:

$>$ To identify clinical outcome and operative situation in patients.

Specific objective:

$>$ To detect risk factors of ectopic pregnancy.

$>$ To evaluate operative findings of the patients 


\section{Materials and Methods:}

This was a descriptive study. This study was conducted at tertiary medical College \& Hospital, from January 2015 to December, 2018. During the study 200 patients data was collected and sampling technique was purposive

Inclusion criteria are Clinically suspected ectopic pregnancy and Clinically diagnosed ectopic pregnancy supported by positive urinary pregnancy test or serum -hCG and USG findings.

Exclusion criteria are Patients who were clinically suspected but laparotomy findings ruled out ectopic pregnancy and Ethical consideration- Ethical issue will be addressed duly with due consent from the patient.

Data collection procedure:

$>$ After taking informed consent from each patient, a very careful history with particular attention to sociodemographic, menstrual, obstetric and contraceptive history, a through physical examination was done and diagnosis was established clinically in majority of cases. Pregnancy test and ultrasonography were done in most cases to support the clinical diagnosis. Hemoglobin estimation and blood grouping were done in all cases.

\section{Statistical analysis:}

$>$ Data were analyzed in computer based programme Statistical Analysis for Social Science (SPSS) for windows version 12 .

\section{Results:}

In table-I shows parity in patients with ectopic pregnancy where the peak percentage was among who are Para 2 $(41.26 \%)$ and incidence is low (3.74\%) among those who are nulliparous. The following table is given below in detail:

Table-I: Parity in patients with ectopic pregnancy.

\begin{tabular}{ll}
\hline Parity & Percentage \\
\hline 0 & $3.74 \%$ \\
1 & $6.25 \%$ \\
2 & $41.25 \%$ \\
3 & $26.26 \%$ \\
4 & $13 \%$ \\
5 or $>5$ & $9.5 \%$ \\
\hline
\end{tabular}

In figure-1 shows social-economic status of the patients where most of the patients $(75.1 \%)$ in this study belong to low economy and only $2.5 \%$ belongs to higher economy. The following figure is given below in detail:

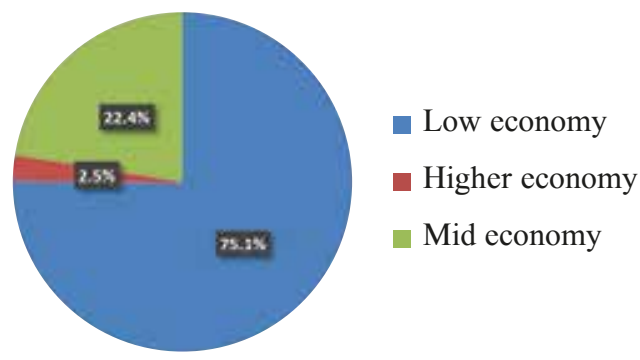

Figure-1: Social-economic status of the patients.
In table-II shows risk factors of ectopic pregnancy where history of pelvic infection $(26.26 \%)$, induced abortion (17.4\%), previous MR (16.26\%) and sub fertility (11.25\%) constitute the main bulk of risk factors. The following table is given below in detail:

Table-II: Risk factors of ectopic pregnancy.

\begin{tabular}{ll}
\hline Risk Factors & Percentage \\
\hline Pelvic infection & $26.26 \%$ \\
Induce abortion & $17.4 \%$ \\
Previous MR & $16.26 \%$ \\
Sub fertility & $11.24 \%$ \\
IUCD insertion & $11.26 \%$ \\
D\&C & $10.1 \%$ \\
LUCS & $6.24 \%$ \\
Any pelvic surgery- & $3.76 \%$ \\
Appendectomy, ovarian cystectomy, tubal ligation. & \\
Endometriosis & $2.4 \%$ \\
Previous ectopic pregnancy & $1.26 \%$ \\
\hline
\end{tabular}

In figure-2 shows symptoms of ectopic pregnancy where abdominal pain $(96.24 \%)$ is the leading symptom symptoms of ectopic pregnancy. The following figure is given below in detail:

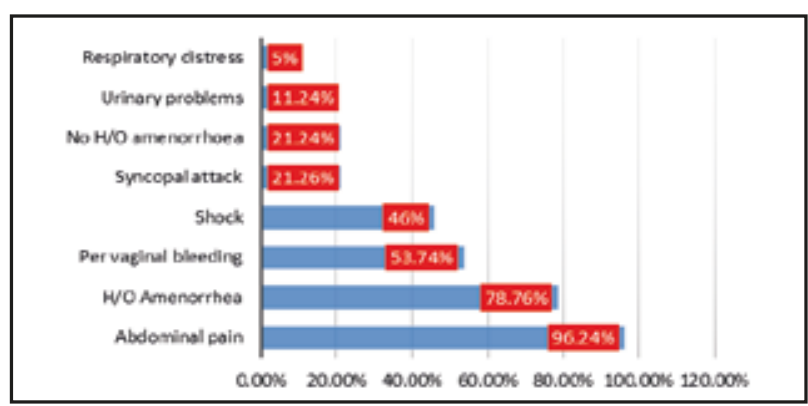

Figure-2: Symptoms of ectopic pregnancy.

In table-III shows signs of ectopic pregnancy where most of the patients $(96.26 \%)$ has abdominal tenderness \& cervical excitation test was positive $94.99 \%$ cases. The following table is given below in detail:

Table-III: Signs of ectopic pregnancy.

\begin{tabular}{ll}
\hline Signs & Percentage \\
\hline Anaemia & $93.74 \%$ \\
Abdominal tenderness & $96.26 \%$ \\
P/V bleeding & $51.24 \%$ \\
Cervical exhibition test & $94.99 \%$ \\
uterine enlargement & $48.76 \%$ \\
Adnexal lump & $35.1 \%$ \\
Fullness of pouch of Douglas & $51.25 \%$ \\
\hline
\end{tabular}

In figure-3 shows tube affected in the patients where right sided tube $(54.5 \%)$ has been found affected more than the left. The following figure is given below in detail:

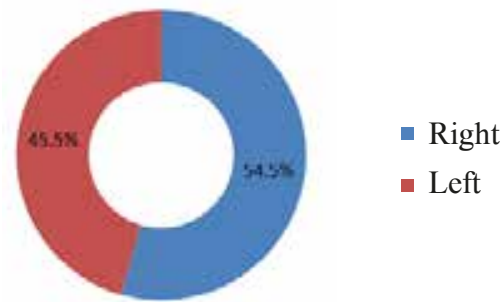

Figure-3: Tube affected in the patients. 
In table- IV shows types of operation where all cases were managed surgically. Laparotomy followed by right sided salphinogectomy $(40.40 \%)$ was the most common operation. The following table is given below in detail:

\section{Table-IV: Types of operation.}

\begin{tabular}{llc}
\hline Types of operation & Percentage & Frequency \\
\hline Laparotomy: & & 80 \\
> Right sided salphinogectomy & $40.40 \%$ & \\
> Left sided salphinogectomy & $36.45 \%$ & \\
> Peritoneal toileting in tubal abortion & $4.40 \%$ & \\
\hline Laparoscopy: & & 20 \\
> Right sided & $14.35 \%$ & \\
> Left sided & $4.10 \%$ & \\
> Salphinogostomy & $0.3 \%$ & \\
\hline
\end{tabular}

In figure-4 shows per operative findings in ectopic pregnancy where most of the cases $(88.10 \%)$ were hemoperitoneum. Followed by tubal ruptured $8.5 \%$, tubal abortion cases were $2.5 \%$, ovarian ectopic cases were $.6 \%$, heterogeneous pregnancy cases were $.2 \%$ and scar ectopic cases were $.1 \%$. The following figure is given below in detail:

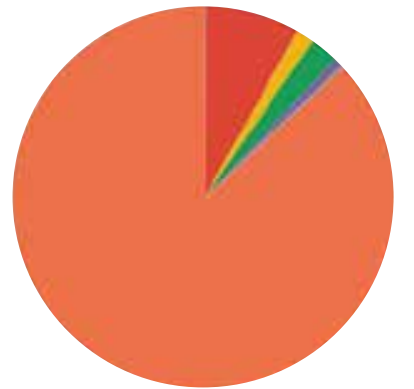

- Scar ectopic
- Tubal ruptured
- Tubal unruptured
- Tubal abrotion
- Ovarian ectopic
- Heterogeneous pregnancy
- Hemoperitoneum

Figure-4: Per operative findings in ectopic pregnancy

In table-V shows Types management of the patients where most of the cases managed by laparotomy (79.9\%). Followed by $18.1 \%$ laparoscopy and under conservative management, $2 \%$ methotrexate therapy were used. The following table is given below in detail:

Table-V: Types of management of the patients

\begin{tabular}{ll}
\hline Types of management & Percentage \\
\hline Laparotomy & $79.9 \%$ \\
Laparoscopy & $18.1 \%$ \\
Conservative management: & \\
Methotrexate therapy & $2 \%$ \\
\hline
\end{tabular}

\section{Discussion}

The frequency of ectopic pregnancy has been increasing worldwide, varies country to country even place to place in the same country, even place to place in the same country, such as in Jamaica 1 in 28 deliveries ${ }^{9,10,11}$. In this study out of 200 patients most of them belong to 30 years $(19.7 \%)$ age group. In one study reported that $65 \%$ of cases were between the ages of 26-35 years ${ }^{12}$. And other report identified that $38 \%$ of the patients were in age group 26- 30 years ${ }^{13}$. In a local study of 300 cases showed that $79 \%-99 \%$ patients in 15-34 years age group ${ }^{14}$. In this study we found that the peak percentage was among who are Para 2 the $(41.26 \%)$ and incidence is low (3.74\%) among those who are nulliparous. American Journal of Epidemiology showed different observation from us that para- 0 was $39.5 \%$ and para- $135.6 \%{ }^{15}$. But many other study also showed similar result from us that higher incidence of ectopic pregnancy was present among women of para-2 ${ }^{12,14}$. In one study they reported that ectopic pregnancy was more commonly found in women of low economic status with $90.3 \%{ }^{15}$. During the study we also found that most of the patients (75.1\%) belong to low economy and only $2.5 \%$ belongs to higher economy. In this study we found that $63.74 \%$ of the patients were illiterate. Also $26.26 \%$ were primary passed. Only $1.26 \%$ patients were graduate. American Journal of epidemiology showed similar result that primary $7.2 \%$, secondary $69.5 \%$ and higher $23.3 \%{ }^{16}$. One study reported that patients in ectopic pregnancy were higher in urban areas rather rural areas ${ }^{17}$ which supports our study where we found that $58.6 \%$ patients' lives in urban area and only $39.9 \%$ patients' lives in rural. During the study we identified that major risk factor for ectopic pregnancy in patients who had history of pelvic infection 26.26\%, induced abortion $17.4 \%$, previous MR $16.26 \%$ and sub fertility $11.25 \%$. Which is similar to other study which reported that. In one study reported that $48 \%$ cases have H/O PID ${ }^{13}$ and another study found PID in $25 \%$ cases $^{9}$. Another study also identified pelvic infection and past history of abortion or MR as the main risk factor for ectopic pregnancy ${ }^{12}$. other report observed $48 \%$ cases had prior induced abortion ${ }^{13}$. The incidence of unsafe abortion by untrained practitioners is quite high which increases the risk of ectopic pregnancy in our country. Subfertility is a risk factor for ectopic pregnancy in our country. History of subfertility was found $4.59 \%$ cases in one study 9 . Use of IUCD is another risk factor for ectopic pregnancy. One study found $17 \%$ cased had H/O IUCD insertion. But no patient had IUCD in situ when presented with ectopic pregnancy $^{18}$. During the experiment we found that abdominal pain $(96.24 \%)$ is the leading symptom symptoms of ectopic pregnancy. One study also found similar outcome that $90.82 \%$ with abdominal pain, $78.57 \%$ with history of amenorrhoea 9 . In the study most of the patients $(96.26 \%)$ has abdominal tenderness \& cervical excitation test was positive $94.99 \%$ cases. Which is similar to other study ${ }^{13}$ ? One study showed that right sided tube was affected more $(79 \%)$ in ectopic pregnancy ${ }^{13}$. Which support our study where we found that right sided tube $(54.5 \%)$ has been found affected more than the left. In the ectopic pregnancy we identified that laparotomy followed by right sided salphinogectomy $(40.40 \%)$ was the most common operation, which is similar to one study ${ }^{19}$. In ruptured ectopic pregnancy hemoperitoneum is one of the life threatening situations which was very common in Bangladesh now a days ${ }^{20}$. 
During the study, we also found that most of the cases $(87.10 \%)$ were hemoperitoneum. Followed by tubal ruptured $8 \%$, tubal abortion cases were $2.5 \%$, ovarian ectopic cases were $.6 \%$, heterogeneous pregnancy cases were $.2 \%$ and scar ectopic cases were .1\%. Many case report showed similar type of outcome like us ${ }^{20,21}$ but other study reported that ruptured cases were $74.86 \%$ and tubal abortion cases were $12.85 \%{ }^{9}$. During surgery we found that $50.1 \%$ patients need ICU support and only $1.5 \%$ patients were dead which quiet similar to one study where they found assessed mortality rate of ectopic pregnancy is between 2 and 4/1000 during the study ${ }^{22}$.

\section{Conclusion}

After many investigation and analysis we can conclude that quick diagnosis, categorizing of underlying risk factors and timely intervention in the form of surgical treatment will help in minimizing the mortality rate associated with ectopic pregnancy.

\section{Conflict of Interest: None.}

\section{Acknowledgment:}

We would like to thank tertiary medical college \& hospital students for their help in data collection.

\section{References:}

1. Yeasmin MS, Uddin MJ, Hasan E. A clinical study of ectopic pregnancies in a tertiary care hospital of Chittagong, Bangladesh. Chattagram Maa-O-Shishu Hospital Medical College Journal. 2014 Nov 28; 13(3):1-4. https://doi.org/10.3329/cmoshmcj.v13i3.20993

2. Qyasian A, Mohammadi Z, Giardino L, Palazzi F, Shalavi S, Sabbaghi S, et al. Nigerian Journal of Medicine. 2014 Jul; 23(3).

3. Lalchandani S, Geary M, O'Herlihy C, Sheil O. Conservative management of placenta accreta and unruptured interstitial cornual pregnancy using methotrexate. European Journal of Obstetrics \& Gynecology and Reproductive Biology. 2003 Mar 26;107(1):96-7.

https://doi.org/10.1016/S0301-2115(02)00241-5

4. Murray H, Baakdah H, Bardell T, Tulandi T. Diagnosis and treatment of ectopic pregnancy. Cmaj. 2005 Oct 11;173(8):905-12.

https://doi.org/10.1503/cmaj.050222

PMid:16217116 PMCid:PMC1247706

5. Goldner TE, Lawson HW, Xia Z, Atrash HK. Surveillance for ectopic pregnancy-United States, 1970-1989. MORBIDITY AND MORTALITY WEEKLY REPORT: CDC Surveillance Summaries. 1993 Dec 17:73-85.

6. Jurkovic D, Wilkinson H. Diagnosis and management of ectopic pregnancy. BMJ. 2011 Jun 10; 342:d3397.

https://doi.org/10.1136/bmj.d3397

PMid:21665933
7. Grudzinskas JG. Miscarriage, ectopic pregnancy and trophoblastic disease. Dewhurst's textbook of obstetrics and gynaecology for postgraduate. London: Blackwell. 1999 Dec 23:61-76.

8. Sivalingam VN, Duncan WC, Kirk E, Shephard LA, Horne AW. Diagnosis and management of ectopic pregnancy. J Fam Plann Reprod Health Care. 2011 Oct 1;37(4):231-40.

https://doi.org/10.1136/jfprhc-2011-0073

PMid:21727242 PMCid:PMC3213855

9. Vyas PS \& Vaidya P. "Epidemiology, Diagnosis and Management of Ectopic pregnancy" Research Articles. 1998; 1-11.

10. Ectopic pregnancy: Learn more on Ectopic symptoms and treatment.

http://w.w.w.women's-health,co.UK/ectopic,asp. 2007:1-6. 11. Medical Encyclopedia: "Ectopic Pregnancy", http:// w.w.w. n/m.nih.Gov/medline plus/print/ency/ article/ 000895. htm 2007; 1-3.

12. Rather, Gousia Rahim, Yudhvir Gupta, and Subash Bardhwaj. "Patterns of lesions in hysterectomy specimens: a prospective study." JK science. (2013); 15( 2) : 63.

13. Nahar K, Talukder T, Sultana S, Hossain MA. Study on Risk Factors, Clinical Presentation \& Operative Management of Ectopic Pregnancy. Bangladesh Journal of Obstetrics \& Gynaecology. 2013;28(1):9-14.

https://doi.org/10.3329/bjog.v28i1.29932

14. Milunsky A, Milunsky JM. Genetic counseling: preconception, prenatal, and perinatal. Genetic Disorders and the Fetus: Diagnosis, Prevention and Treatment. JHU Press: Baltimore, MD. 2004:1-65.

https://doi.org/10.1002/9781118981559.ch1

15. Stulberg DB, Zhang JX, Lindau ST. Socioeconomic disparities in ectopic pregnancy: predictors of adverse outcomes from Illinois hospital-based care, 2000-2006. Maternal and child health journal. 2011 Feb 1;15(2):234-41.

https://doi.org/10.1007/s10995-010-0579-6

PMid:20177756 PMCid:PMC2928390

16. Bouyer J, Coste J, Shojaei T, Pouly JL, Fernandez H, Gerbaud L, et al. Risk factors for ectopic pregnancy: a comprehensive analysis based on a large case-control, population-based study in France. American Journal of Epidemiology. 2003 Feb 1;157(3):185-94.

https://doi.org/10.1093/aje/kwf190

PMid:12543617

17. Garrett AM, Vukov LF. Risk factors for ectopic pregnancy in a rural population. Family medicine. 1996 Feb;28(2):111-3.

18. Al-Daheen G. Ectopic pregnancy, A Prospective Study In Al-Batool Teaching Hospital In Mosul-Iraq. Al-Kindy College Medical Journal. 2007;4(1):63-9. 
19. Marchbanks, Polly A., John F. Annegers, Carolyn B. Coulam, Janette H. Strathy, and Leonard T. Kurland. "Risk factors for ectopic pregnancy: a population-based study." Jama. (1988);259(12): 1823-1827.

https://doi.org/10.1001/jama.1988.03720120027030

PMid:3343790

20. Al-Daheen G. Ectopic pregnancy, A Prospective Study In Al-Batool Teaching Hospital In Mosul-Iraq. Al-Kindy College Medical Journal. 2007;4(1):63-9.
21. Hanna WA, Myles TJ. Spontaneous intraperitoneal haemorrhage during pregnancy: report of three cases. British medical journal. 1964 Apr 18;1(5389):1024.

https://doi.org/10.1136/bmj.1.5389.1024

PMid:14108474 PMCid:PMC1814219

22. Schneider J, Berger CJ, Cattell CR. Maternal mortality due to ectopic pregnancy. A review of 102 deaths. Obstetrics and gynecology. 1977 May;49(5):557-61. 